\title{
EFEITO DA UTILIZAÇÃO DA ESCORIA DE ACIARIA BSSF COMO AGREGADO MIUDO NAS PROPRIEDADES MECANICAS DE ARGAMASSAS MISTAS
}

\author{
ALVES AMANCIO, FELIPE \\ Mestre em Engenharia Civil \\ Universidade Federal do Ceará \\ Ceará; Brasil \\ felipeaamancio@hotmail.com
}

\author{
RODRIGUES DE OLIVEIRA DIAS, ALISSON \\ Mestre em Engenharia Civil \\ Universidade Federal do Ceará \\ Ceará; Brasil \\ rodrigues_alisson@live.com
}

\author{
D. ALEXANDRE LIMA, DOUGLAS \\ Graduando em Engenharia Civil \\ Universidade Federal do Ceará \\ Ceará; Brasil \\ douglasalexandre@alu.ufc.br
}

\author{
BEZERRA CABRAL, ANTONIO EDUARDO \\ Professor, Doutor \\ Universidade Federal do Ceará \\ Ceará; Brasil \\ eduardo.cabral@alu.br
}

\author{
MESQUITA, ESEQUIEL \\ Professor, Doutor \\ Universidade Federal do Ceará \\ Ceará; Brasil \\ Mesquita.e@outlook.com
}

\section{RESUMO}

O objetivo deste trabalho foi investigar o efeito da utilização da escória de aciaria Baosteel Slag Short Flow (BSSF) como agregado miúdo nas propriedades de resistência à compressão, módulo de elasticidade e velocidade de propagação ultrassônica de argamassas de revestimento. O trabalho experimental contou com ensaios de caracterização físico-química da escória de aciaria BSSF produzida na Companhia Siderúrgica do Pecém em Fortaleza, Ceará, bem como a avaliação das propriedades das argamassas. Os traços investigados foram 1:1:4, 1:1:6 e 1:1:8 nas proporções volumétricas de cimento, cal e agregado miúdo natural, o qual foi substituído nos teores de $0 \%, 20 \%, 40 \%$ e $60 \%$. Por fim, os resultados foram analisados estatisticamente por meio da Análise de Variância (ANOVA). Pode-se constatar que as argamassas com maiores teores de escória de aciaria BSSF demandaram uma maior quantidade de água para obter o espalhamento na mesa de consistência, o qual foi fixado em $260 \pm 5 \mathrm{~mm}$. No estado endurecido, a substituição da areia por escória gerou um aumento significativo no módulo de elasticidade dinâmico e na velocidade de propagação ultrassônica. Em relação a resistência à compressão e a tração na flexão, com a realização da ANOVA, pode constatar que a substituição não exerce influência significativa nestas propriedades.

Palavras-chave: Escória de aciaria BSSF, Argamassa, Propriedades mecânicas

\section{ABSTRACT}

The aim of this work was to investigate the effect of using Baosteel Slag Short Flow (BSSF) steel slag as a small aggregate on the properties of compressive strength, modulus of elasticity and ultrasonic propagation speed of coating mortars. The experimental work included physical-chemical characterization tests of BSSF steel slag produced at Companhia Siderúrgica do Pecém in Fortaleza, Ceará, as well as the evaluation of mortar properties. The traces investigated were 1:1:4, 1:1:6 and 1:1:8 in the volumetric proportions of cement, lime and natural small aggregate, which was replaced in the levels of $0 \%, 20 \%, 40 \%$ and $60 \%$. Finally, the results were statistically analyzed using the Analysis of Variance (ANOVA). It can be seen that the mortars with higher contents of BSSF steel slag required a greater amount of water to obtain the spreading on the consistency table, which was fixed at $260 \pm 5 \mathrm{~mm}$. In the hardened state, the substitution of sand for slag generated a significant increase in the dynamic modulus of elasticity and in the speed of ultrasonic propagation. In relation to the resistance to compression and traction in bending, with the realization of ANOVA, it can be verified that the substitution does not exert a significant influence on these properties.

Keywords: BSSF steel slag, Mortar, Mechanical Properties. 


\section{INTRODUÇÃO}

No Brasil, estimou-se que a produção de aço bruto tenha sido na ordem de 34,4 toneladas em 2017 , ocupando a $9^{\circ}$ posição no ranking de maiores produtores mundiais (BRASIL, 2016). A indústria metalúrgica, apesar do seu papel de extrema importância na economia, produz anualmente grandes quantidades de escória, que representam um problema para a fábrica e para o meio ambiente (QASRAWI, 2014). Para cada tonelada de aço bruta produzida, estima-se uma geração de 130 a $200 \mathrm{~kg}$ de escória (FARAONE et al, 2009).

A necessidade de dar um destino adequado a esses resíduos gera custos de transporte, processamento, armazenamento, disposição final, e futuramente trará impactos ao meio ambiente (LOHANI, 2012; QASRAWI,2014; CHEN et al., 2014). Ademais, esse material possui boas caracteristicas físicas, como a alta resistência e durabilidade, o que demonstra um potencial para ser utilizada como agregados na indústria da construção civil (TOSSAVAINEN et al 2007; WANG, 2010; ABU-EISHAH; EL-DIEB; BEDIR, 2012).

Nesse viés, o setor da construção civil se apresenta como uma das indústrias mais interessadas na utilização desse tipo de resíduo devido ao seu menor custo e menor impacto ambiental pela possibilidade de se reduzir a extração de areias em rios, que causa inúmeros danos ao meio ambiente como desmatamento e remoção do solo (CHAVES; SANTOS, 2007), além desses impactos, a quantidade de agregados naturais com propriedades adequadas para serem empregadas na construção civil tem se tornado crítica em muitas áreas urbanas.

Aliado a esses fatores, o aumento das distâncias entre os depósitos de material natural e os locais de alocação de novas construções tem favorecido na elevação do preço do produto final, devido aos custos com transporte (HANSEN, 1992). Essa busca pelo uso de materiais alternativos aumentou significativamente com a crescente conscientização ambiental e pela busca por novas soluções que combinem crescimento econômico e preservação do patrimônio natural (LOHANI et al., 2012; PEDRO et al., 2013).

Dessa forma, faz-se necessário o estudo do comportamento desse resíduo da indústria siderúrgica na aplicação no setor da construção civil, obtendo-se assim, redução nos custos dos produtos da construção, além de minimizar os impactos ambientais ocasionados pelo consumo exacerbado de areia na produção de argamassas e concretos. Neste sentido, o presente trabalho visou analisar as propriedades mecânicas das argamassas de revestimento de cimento Portland, com a substituição, em volume, da areia natural por escória de aciaria BSSF nas proporções de 0\%, 20\%, 40\%, e 60\% nos traços 1:1:4, 1:1: e 1:1:8.

\section{PROGRAMA EXPERIMENTAL}

Nesta pesquisa foi utilizado cimento Portland CP V - ARI. As Tabelas 1 e 2 apresentam as características físicas e químicas do cimento, fornecidos pelo fabricante.

Tabela 1 - Características físicas e químicas do cimento a ser utilizado

\begin{tabular}{c|c|c|c}
\hline Ensaio & Norma & Resultado & Especificação - Norma NBR 16697:2018 \\
\hline Perda ao fogo & NM 18/12 & $4,39 \%$ & $\leq 6,5$ \\
\hline Óxido de Magnésio - MgO & NM 11-2/12 & $4,17 \%$ & $\leq 6,5$ \\
\hline Anidrido Sulfúrico - SO3 & NM 16/12 & $3,24 \%$ & $\leq 4,5$ \\
\hline Resíduo Insolúvel & NM 15/12 & $0,69 \%$ & $\leq 3,5$ \\
\hline Anidrido Carbônico & $11578 / 91$ & $2,97 \%$ & $\leq 5,5$ \\
\hline Massa específica & NM 23/01 & $3,06 \mathrm{~g} / \mathrm{cm} 3$ & Não aplicável \\
\hline Finura (\#200) & $11579 / 12$ & $0,20 \%$ & $\leq 6,0$ \\
\hline Finura (\#325) & $12826 / 14$ & $4,80 \%$ & Não aplicável \\
\hline Início de pega & NM 65/03 & $2: 15 \mathrm{~h}: \mathrm{min}$ & $\leq 1: 00$ h:min \\
\hline Fim de pega & NM 65/03 & $3: 45 \mathrm{~h}: \mathrm{min}$ & $\leq 10: 00$ h:min \\
\hline Expansibilidade a quente & $11582 / 16$ & $0,00 \mathrm{~mm}$ & $\leq 5,0$ \\
\hline
\end{tabular}


Tabela 2 - Resistência à compressão em MPa do cimento a ser utilizado

\begin{tabular}{c|c|c}
\hline Idade (dias) & $\begin{array}{c}\text { Média } \\
(\mathbf{M P a})\end{array}$ & Especificação - Norma NBR 16697:2018 \\
\hline 1 & 25,9 & $\geq 14,0 \mathrm{Mpa}$ \\
\hline 3 & 36,6 & $\geq 24,0 \mathrm{Mpa}$ \\
\hline 7 & 44,3 & $\geq 34,0 \mathrm{Mpa}$ \\
\hline 28 & 53,2 & - \\
\hline
\end{tabular}

A água foi proveniente do sistema de abastecimento de água da cidade de Fortaleza, Ceará. A areia utilizada foi extraída de rio, proveniente da Região Metropolitana Fortaleza, enquanto a escória de aciaria utilizada foi do tipo BSSF, proveniente da Companhia Siderúrgica do Pecém - CSP. O material foi seco previamente em estufa à $105 \pm 5^{\circ} \mathrm{C}$ até a constância de massa. Após seca, foi realizada o peneiramento da escoria, conforme estabelece a NBR 248 (ABNT, 2003).

Em seguida, foi realizado o ajuste da distribuição granulométrica da escória de aciaria BSSF para se igualar ao da areia natural, no intuito de evitar influência do tamanho dos grãos na trabalhabilidade e demais propriedades das argamassas.

A curva granulométrica dos agregados miúdos é apresentada na Figura 1, demonstrando que se enquadram na zona utilizável e um pequeno trecho na zona ótima, conforme NBR 7211 (ABNT, 2009). As características dos agregados estão descritas nas Tabelas 3 e 4. Destaca-se que as propriedades de índice de vazios, a porosidade e o fator de empacotamento foram determinados conforme CARASEK et al (2016). Valores próximos foram obtidos por CARASEK et al (2018) ao analisar areia natural de Diâmetro máximo característico (DMC) na ordem de 2,36 mm, encontrou valores de $47 \%$ e $53 \%$ para a porosidade e fator de empacotamento, respectivamente.

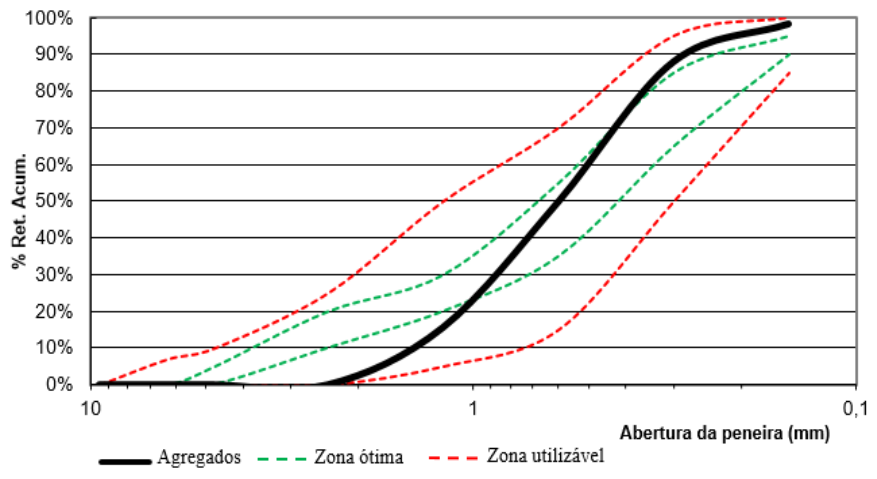

Figura 1: Curva granulométrica dos agregados

Tabela 3 - Características físicas dos agregados

\begin{tabular}{ccccc}
\hline Ensaio & Norma/ Método & Unid & Areia & Escória \\
\hline DMC & NM 248 (ABNT, 2003) & $\mathrm{mm}$ & 2,36 & 2,36 \\
\hline Módulo de finura & NM 248 (ABNT, 2003) & Adim. & 2,52 & 2,52 \\
\hline Massa unitária & NBR NM 45 (ABNT, 2006) & $\mathrm{g} / \mathrm{cm}^{3}$ & 1,41 & 2,08 \\
\hline Absorção de água & NBR NM 52 (ABNT, 2009) & $\%$ & 0,9 & 2,1 \\
\hline Massa específica & NBR NM 52 (ABNT, 2009) & $\mathrm{g} / \mathrm{cm}^{3}$ & 2,59 & 3,86 \\
\hline Teor de material pulverulento & NBR NM 46 (ABNT, 2003) & $\%$ & 1,0 & 1,3 \\
\hline índice de vazios, & CARASEK et al (2016) & Adim. & 0,84 & 0,86 \\
\hline Porosidade & CARASEK et al (2016) & $\%$ & 46 & 46 \\
\hline Fator de empacotamento & CARASEK et al (2016) & $\%$ & 54 & 54 \\
\hline
\end{tabular}

Em relação à caracterização química da escória de aciaria BSSF, foi realizada a Fluorescência de Raios X (FRX), apresentada na Tabela 4. Constata-se que a escória é constituída basicamente de $\mathrm{Fe} 2 \mathrm{O} 3, \mathrm{CaO}$ e $\mathrm{SiO} 2$ ( \pm 92\%), valores próximos foram obtidos por CAMPOS et al (2018) utilizando a mesma escória proveniente da CSP. 
Tabela 4 - Composição química da escória de aciaria BSSF

\begin{tabular}{lllllllllll}
\hline Óxidos & $\mathrm{Al}_{2} \mathrm{O}_{3}$ & $\mathrm{SiO}_{2}$ & $\mathrm{P}_{2} \mathrm{O}_{5}$ & $\mathrm{~K}_{2} \mathrm{O}$ & $\mathrm{CaO}$ & $\mathrm{TiO}_{2}$ & $\mathrm{Cr}_{2} \mathrm{O}_{3}$ & $\mathrm{MnO}$ & $\mathrm{Fe}_{2} \mathrm{O}_{3}$ & $\mathrm{Co}_{2} \mathrm{O}_{3}$ \\
\hline Amostra (\%) & 0.63 & 5.84 & 1.01 & 0.04 & 33.46 & 0.63 & 0.21 & 5.09 & 52.98 & 0.12 \\
\hline
\end{tabular}

A escória de aciaria BSSF foi ensaiada ainda quanto à expansibilidade, conforme a NBR 16697 (ABNT, 2018). O ensaio foi realizado com base no ensaio de determinação da expansibilidade do cimento pelo método de Le Chatelier (ABNT NBR 11582:2016), sendo adotado um teor de substituição de cimento por escória de aciaria BSSF de 50\%, em volume, conforme defende Mehta (1999) apud Masuero (2001). Destaca-se que a mesma não apresentou expansão a frio e em relação à expansão a quente, todos os resultados obtidos encontraram-se dentro do limite máximo especificado em norma de $5 \mathrm{~mm}$.

Utilizou-se nesta pesquisa argamassas mistas (cimento e cal). Os traços de referência utilizados foram 1:1:4, 1:1:6 e 1:1:8. Destaca-se que a definição partiu das proporções que são empregadas nas construtoras da cidade de Fortaleza. Estes traços são apresentados em massa combinado com volume. Por exemplo, o traço 1:1:4 constituído de 1 saco de cimento (50 $\mathrm{kg}$ de cimento), 1 de cal ( $20 \mathrm{~kg}$ de cal) e 4 padiolas de $40 \mathrm{~L}$ de areia úmida.

Fixou-se o índice de consistência medido por meio da mesa de abatimento em $260 \pm 5 \mathrm{~mm}$. A partir deste índice, determinou-se para cada traço a quantidade de água para alcança-la. Em seguida, estes traços foram transformados em massa por meio da massa unitária, no intuito de melhorar a realização dos ensaios no laboratório. Destaca-se ainda, que foi utilizado o inchamento da areia para a conversão do traço de obra utilizado em volume para massa, o qual foi utilizado no laboratório.

A substituição da areia natural por escória de aciaria ocorreu em volume, conforme a equação 01 , sendo m (a massa do material) e $\mathrm{Y}$ (massa específica do material). Os teores de substituição de areia natural por escória de aciaria BSSF foram de $20 \%, 40 \%$ e $60 \%$. Analisou-se ainda um traço de referencia, sem a utilização de escória de aciaria. Os teores foram definidos após ensaios preliminares, pelos quais constatou-se que para os teores de $100 \%$ e $80 \%$ de substituição, as argamassas apresentavam exsudação e baixa trabalhabilidade. A Tabela 5 apresenta as proporções dos traços produzidos, sendo o consumo de água definido conforme a NBR 13276:2016.

$$
\mathrm{M}_{\text {escória }}=\mathrm{M}_{\text {areia }} \frac{\text { Yescória }}{\text { Yareia }}
$$

Tabela 5 - Proporção dos traços ensaiados

\begin{tabular}{|c|c|c|c|c|c|c|c|c|c|c|c|}
\hline \multirow{2}{*}{ Traço } & \multirow{2}{*}{ Ident. } & \multicolumn{5}{|c|}{ Traço unitário em Massa } & \multicolumn{5}{|c|}{ Consumo em kg/m $\mathbf{m}^{3}$} \\
\hline & & Cimento & Cal & Areia & Escória & Água & Cimento & Cal & Areia & Escória & Água \\
\hline \multirow{4}{*}{$1: 1: 4$} & REFD & 1 & 0,4 & 3,13 & 0,00 & 0,79 & 403,0 & 161,2 & 1261,3 & 0,0 & 318,4 \\
\hline & $\mathrm{D} 20$ & 1 & 0,4 & 2,51 & 0,93 & 0,8 & 401,1 & 160,4 & 1006,8 & 373,0 & 320,9 \\
\hline & $\mathrm{D} 40$ & 1 & 0,4 & 1,88 & 1,87 & 0,81 & 399,5 & 159,8 & 751,0 & 747,0 & 323,6 \\
\hline & D60 & 1 & 0,4 & 1,25 & 2,80 & 0,8 & 401,4 & 160,6 & 501,8 & 1124,0 & 321,1 \\
\hline \multirow{4}{*}{$1: 1: 6$} & REFE & 1 & 0,4 & 4,70 & 0,00 & 1,07 & 296,9 & 118,8 & 1395,6 & 0,0 & 317,7 \\
\hline & E20 & 1 & 0,4 & 3,76 & 1,40 & 1,08 & 296,1 & 118,4 & 1113,3 & 414,5 & 319,8 \\
\hline & E40 & 1 & 0,4 & 2,82 & 2,80 & 1,1 & 294,4 & 117,7 & 830,1 & 824,2 & 323,8 \\
\hline & E60 & 1 & 0,4 & 1,88 & 4,20 & 1,09 & 295,2 & 118,1 & 555,1 & 1240,0 & 321,8 \\
\hline \multirow{4}{*}{$1: 1: 8$} & REFF & 1 & 0,4 & 6,27 & 0,00 & 1,38 & 233,4 & 93,4 & 1463,6 & 0,0 & 322,1 \\
\hline & F20 & 1 & 0,4 & 5,01 & 1,87 & 1,41 & 231,9 & 92,8 & 1161,9 & 433,7 & 327,0 \\
\hline & $\mathrm{F} 40$ & 1 & 0,4 & 3,76 & 3,74 & 1,45 & 229,7 & 91,9 & 863,6 & 859,0 & 333,1 \\
\hline & F60 & 1 & 0,4 & 2,51 & 5,60 & 1,56 & 224,1 & 89,6 & 562,4 & 1254,8 & 349,5 \\
\hline
\end{tabular}

Após a determinação dos traços, deu-se início a preparação das argamassas, seguindo os procedimentos preconizados pela NBR 16541 (ABNT, 2016). Após a mistura, foram realizados a moldagem dos corpos de prova prismáticos de dimensões 4,0x4,0x16,0 cm para os ensaios de caracterização das argamassas no estado endurecido na idade de 28 dias. 
As resistências à compressão e à tração na flexão foram realizadas conforme as recomendações da NBR 13279 (ABNT, 2005), tendo sido realizado 3 amostras para a flexão e 6 para a compressão.

O módulo de elasticidade dinâmico (Ed) foi determinando conforme a NBR 15630:2008 (ABNT, 2005). Para este ensaio foram realizadas 3 determinações em corpos de provas distintos. Primeiramente, determinou-se a velocidade de propagação ultrassônica (VPU) por meio do equipamento Pundit Lab+, com frequência dos transdutores na ordem de $54 \mathrm{~Hz}$, conforme Equação 2, sendo L a distância entre os pontos de acoplamento dos transdutores (comprimentos do corpo de prova, em $\mathrm{mm}$ ) e $\mathrm{t}$ - o tempo registrado pelo mostrador digital, em $\mu \mathrm{s}$.

$$
V P L=L / t
$$

Em seguida. O módulo de elasticidade dinâmico foi determinado conforme Equação 3.

$$
E d=\rho \cdot v^{2} \cdot \frac{(1+\mu) \cdot(1-2 \mu)}{1-\mu}
$$

\author{
Sendo: \\ $\rho$ - densidade de massa aparente no estado endurecido da argamassa $\left(\mathrm{kg} / \mathrm{m}^{3}\right)$ \\ $\mathrm{v}$ - velocidade de propagação ultrassônica $(\mathrm{mm} / \mu \mathrm{s})$ \\ $\mu$ - coeficiente de Poisson, sendo usualmente 0,20 nesta equação.
}

O tratamento dos dados foi realizado por meio de análise estatística, com a realização da Análise de variância (ANOVA) no software Statistica 7.0. Primeiramente, realiza-se os resíduos padronizados para os ensaios realizados, no intuito de eliminar os dados espúrios. Tais valores são considerados outliers quando os resíduos padronizados excedem um valor de referência de 1,96 para mais ou para menos (valor crítico para um nível de confiança de 0,05). Após a identificação e descarte dos dados discrepantes, é realizado uma nova rodada de análise no software Statistic ${ }^{\circledR}$ até que todos os pontos fiquem compreendidos no intervalo como aceitável. Por fim, com todos os valores dentro dos limites aceitáveis é realizado a ANOVA para identificar a significância ou não dos resultados obtidos.

\title{
3. RESULTADOS
}

A Figura 2a apresenta a variação da resistência à compressão inversamente proporcional a quantidade de agregado miúdo por aglomerante, como se era esperado os traços mais pobres possuem uma menor resistência à compressão, bem como a resistência a tração na flexão como mostrado na Figura $2 b$.

a)

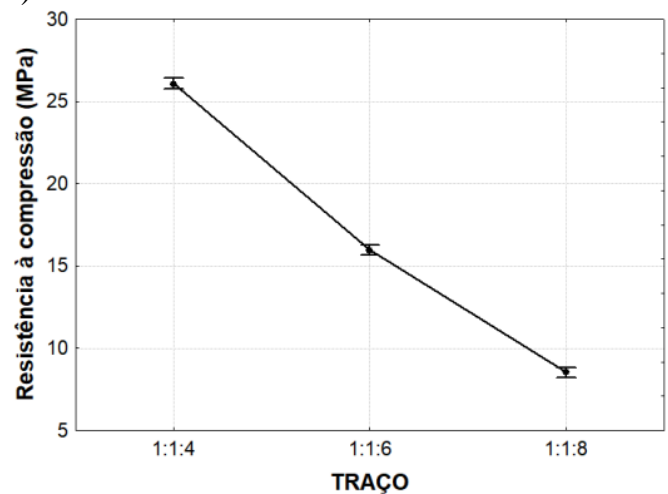

b)

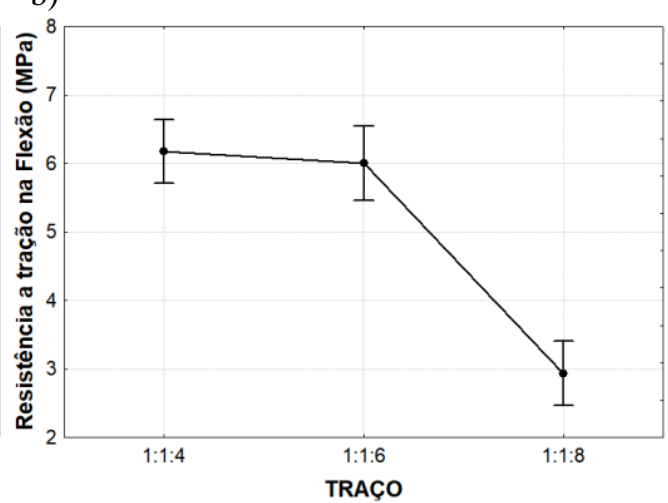

Figura 2: Variação da resistência pela proporção de agregado e aglomerante

A Figura 3 apresenta a influência do teor de substituição da areia natural por escória de aciaria BSSF na resistência à compressão e flexão a tração das argamassas respectivamente. Pode-se constatar pela Figura $3 a$ que o teor de substituição não exerce influência na resistência à compressão, bem como o teor de substituição não exerce influência significativa na resistência a tração na flexão (Figura 3b). 
a)

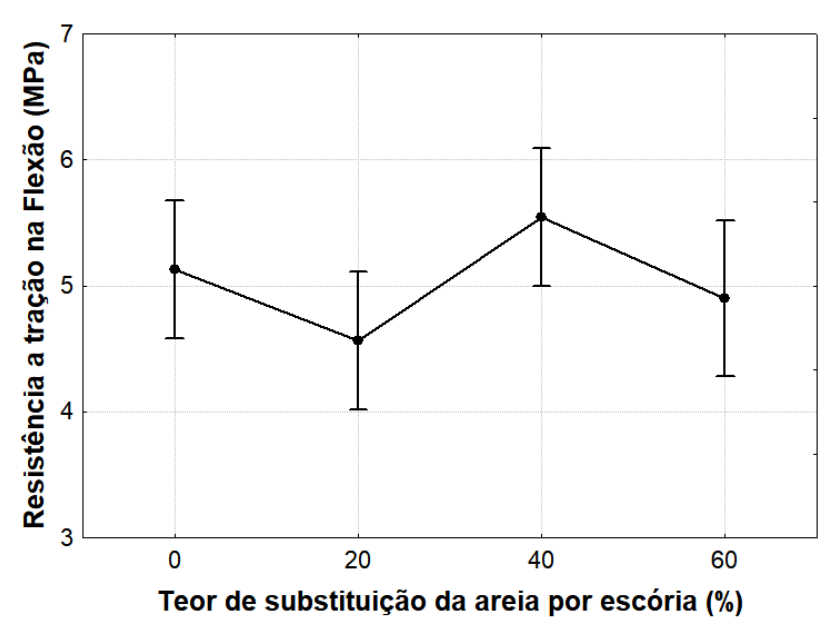

b)

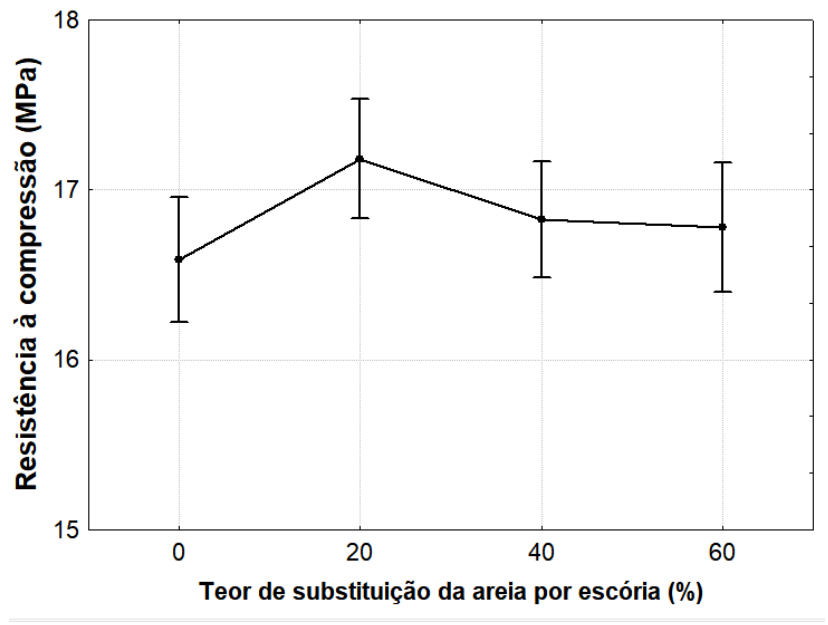

Figura 3: Variação da resistência pelo teor de substituição

A Análise de Variância (Tabelas 6 e 7) constatou, com 95\% de confiabilidade, que o teor de substituição não exerce influência na resistência à compressão e tração na flexão nas argamassas, tendo influência apenas o traço.

Tabela 6: Análise da variância da resistência à compressão das argamassas

\begin{tabular}{c|c|c|c|c|c|c}
\hline Efeito & SQ & GL & MQ & F & Valor - P & Significância \\
\hline Traço & 3283,51 & 2 & 1641,76 & 3168,80 & 0,000000 & S \\
\hline Teor de substituição (\%) & 2,97 & 3 & 0,99 & 1,91 & 0,138444 & NS \\
\hline Traço x teor de substituição (\%) & 23,65 & 6 & 3,94 & 7,61 & 0,000006 & $\mathrm{~S}$ \\
\hline Erro & 27,98 & 54 & 0,52 & - & - & - \\
\hline
\end{tabular}

Legenda: SQ - soma quadrada; GL - Grau de liberdade; MQ - media quadrada; S - significativo; NS - Não significativo.

Tabela 7: Análise da variância da resistência à tração na flexão das argamassas

\begin{tabular}{c|c|c|c|c|c|c}
\hline Efeito & SQ & GL & MQ & F & Valor - P & Significância \\
\hline Traço & 68,0984 & 2 & 34,0492 & 65,143 & 0,000000 & S \\
\hline Teor de substituição (\%) & 3,8682 & 3 & 1,2894 & 2,467 & 0,095241 & NS \\
\hline Traço x teor de substituição & 10,2682 & 6 & 1,7114 & 3,274 & 0,023452 & $\mathrm{~S}$ \\
\hline Erro & 9,440 & 18 & 0,5227 & - & - & - \\
\hline
\end{tabular}

Legenda: SQ - soma quadrada; GL - Grau de liberdade; MQ - media quadrada; S - significativo; NS - Não significativo.

As Figuras $4^{\mathrm{a}}$ e $4 \mathrm{~b}$ apresentma os valores de resistência à compressão para cada teor de substituição de acordo com cada traço. 
a)

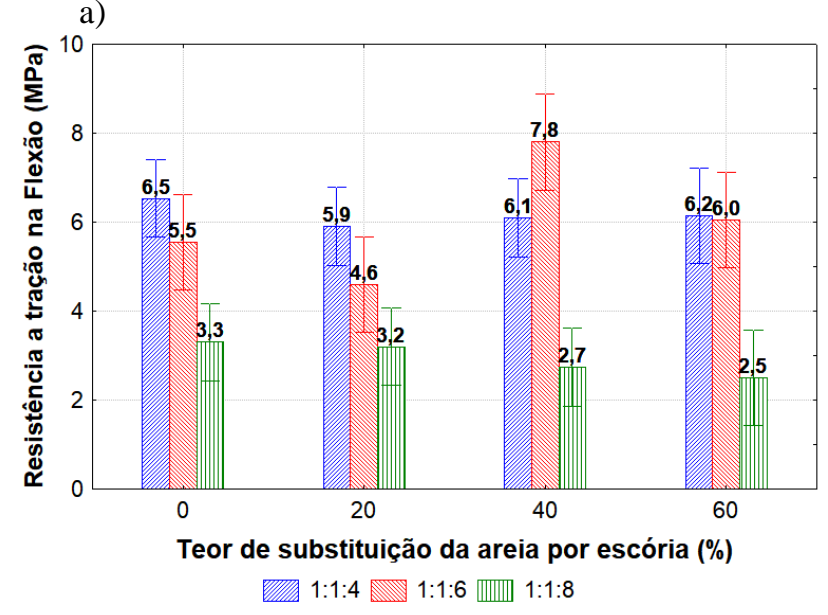

b)

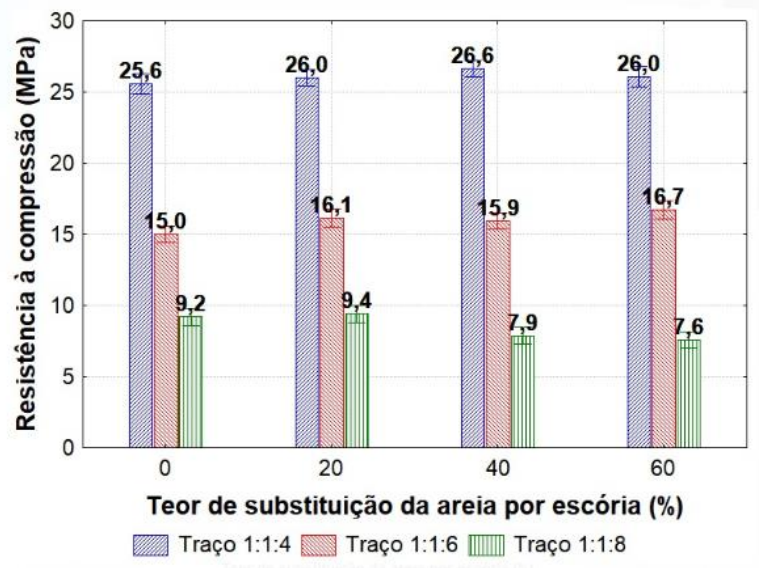

Figura 4: Resistência à compressão das argamassas mistas conforme o traço e o teor de substituição

Estudos realizados (SANTAMARÍA-VICARIO et al., 2016; OUDA; ABDEL-GAWWAD,2017) constataram um aumento da resistência à compressão e a tração na flexão com o aumento de escória. Este aumento foi justificado por OZTURK et al (2018) ao encontrar os maiores valores de resistência para o teor de substituição de $40 \%$, sendo de até $18 \%$ para a resistência à compressão e de $30 \%$ para a flexão, fixando o mesmo fator a/c para todas as argamassas. Os autores explicam que devido a forma irregular dos grãos de escória, e quando estes são misturados com a pasta de cimento, há um melhor intertravamento entre a pasta de cimento e os grãos de escória.

Fato contrário foi constatado por LACERDA (2015), que concluíram que a resistência mecânica da argamassa com agregado de escória foi inferior à argamassa de referência em até em 35\% em 7 dias e 12\% em 28 dias à compressão. Entretanto, no referido trabalho não houve o ajuste granulométrico dos agregados, o que deve ter influenciado nas propriedades mecânicas das argamassas.

Foi possível ainda estabelecer uma correlação linear entre a resistência à tração na flexão e a resistência à compressão das argamassas, com um coeficiente de correlação na ordem de 0,59 (Figura 5). Quanto a classificação conforme a NBR 13281 (ABNT,2005), tanto a resistências à tração na flexão como a compressão todas as argamassas investigadas enquadram-se na mesma categoria, respectivamente nas classes R6 e P6.

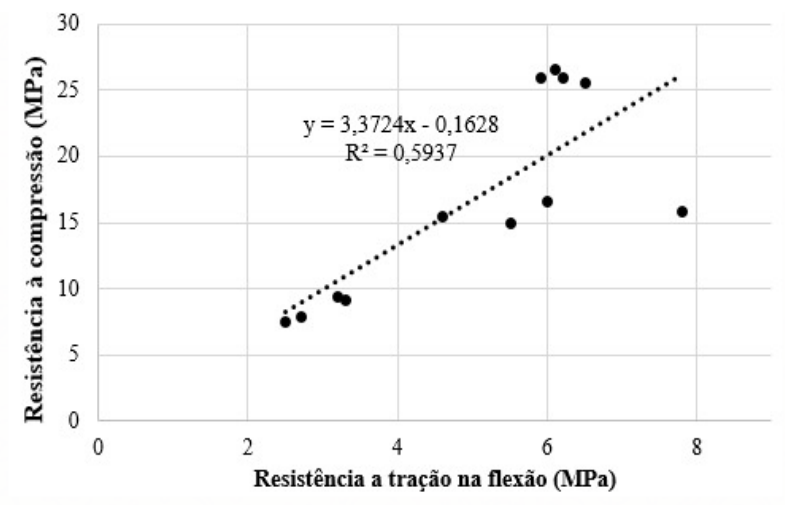

Figura 5: Correlação entre a resistência à compressão e a resistência a tração na flexão.

Em relação a VPU, a ANOVA constatou que o teor de substituição não influencia significativamente na VPU das argamassas (Figura 6). 
a)

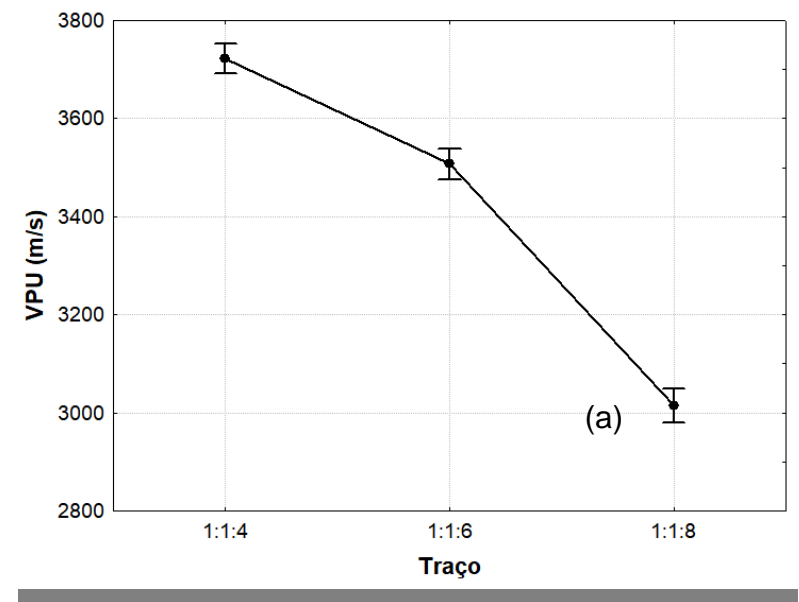

b)

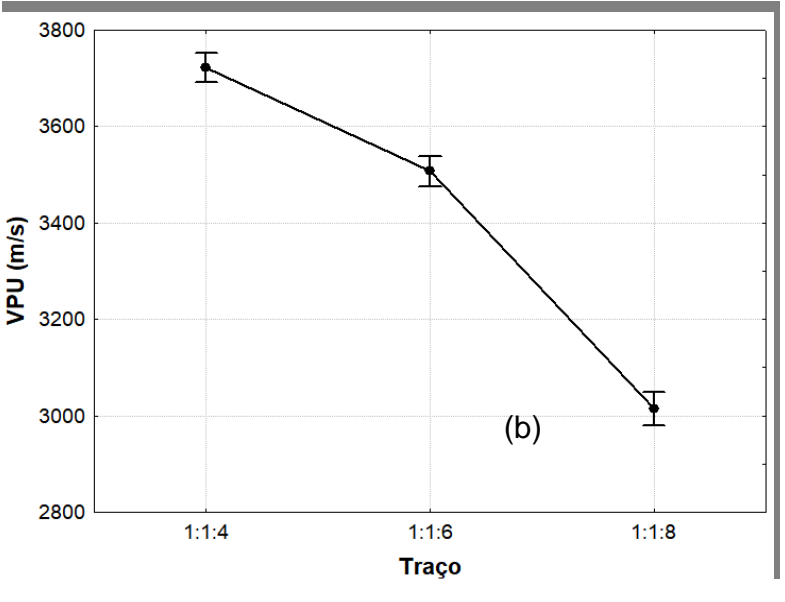

Figura 6: a) Influência do teor de substituição na VPU das argamassas; b) Influência do traço na VPU das argamassas

Quanto a VPU, pode-se constatar com a análise de variância que para as argamassas, o traço não exerce influência significativa na VPU das argamassas. A Figura 7 apresenta o comportamento da VPU conforme o teor de substituição para os traços investigados. Apesar das argamassas com escória apresentarem maior fator a/c, o que influencia na porosidade da argamassa, e consequentemente na VPU, a ANOVA constatou que a substituição não afeta significativamente tal propriedade.

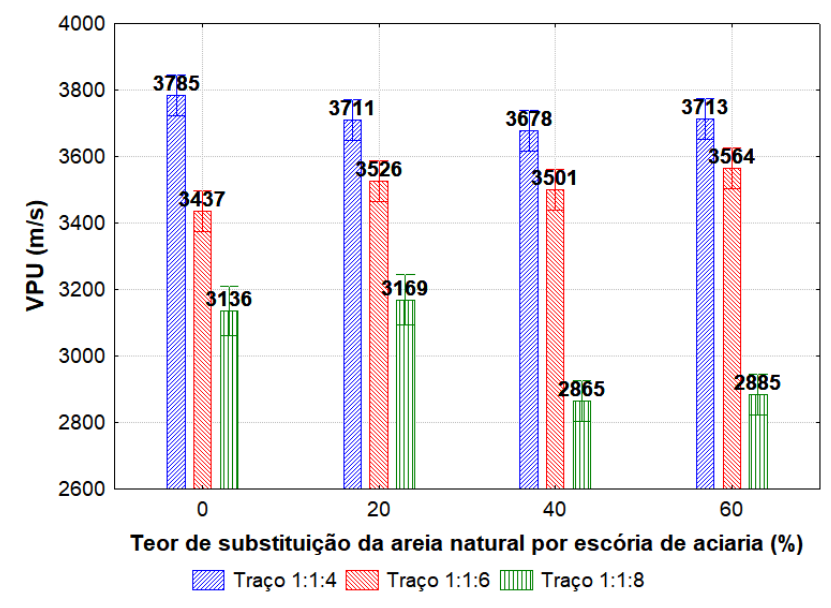

Figura 7: VPU das argamassas de acordo com o traço e o teor de substituição.

Em se tratando do módulo de elasticidade dinâmico, a Figura 8 demonstra a influência do teor de substituição de areia natural por escória de aciaria, bem como do traço no módulo de elasticidade dinâmico para as argamassas mistas. Com o teste da ANOVA, constata-se que o teor de substituição e o traço exercem influência no módulo dinâmico. 
a)

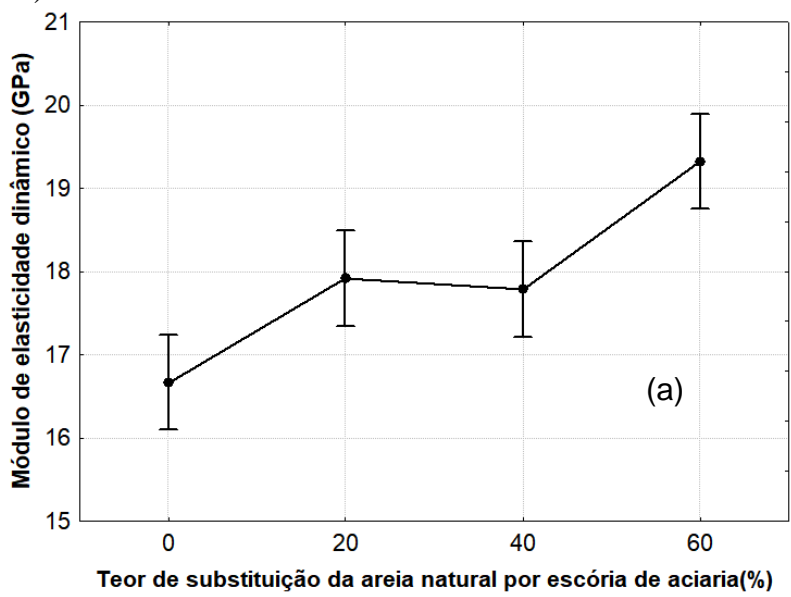

b)

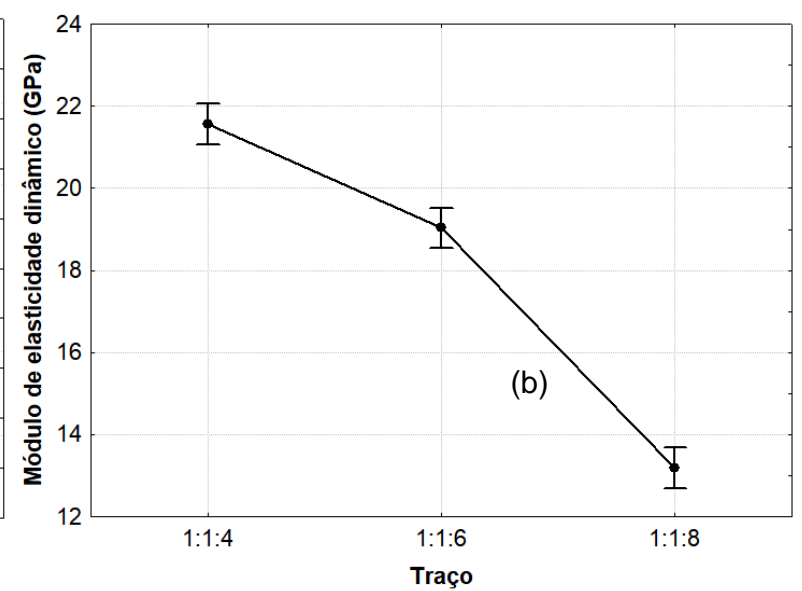

Figura 8: a) Influência do teor de substituição no módulo de elasticidade dinâmico das argamassas; b) Influência do traço no módulo de elasticidade dinâmico das argamassas.

A Figura 9 apresenta o comportamento do módulo de elasticidade dinâmico das argamassas de acordo com o traço e teor de substituição. O módulo de elasticidade dinâmico apresentou valores elevados, sendo os traços com maiores consumos de cimento os que apresentaram os maiores valores de módulo de elasticidade, devido ao aumento da rigidez. Outra justificativa para os altos valores do módulo de elasticidade se deve ao baixo teor de ar das argamassas. As bolhas de ar aumentaram a capacidade de deformação da argamassa e reduzem sua rigidez (HADDAD et al., 2016). Ao passo que conforme a Tabela 7, os valores de teor de ar ficaram compreendidos entre 1 e $5 \%$. Para argamassas de revestimento produzidas sem aditivos, seja argamassas simples ou mistas, o teor de ar geralmente encontra-se em torno de 2 a $5 \%$ do volume total.

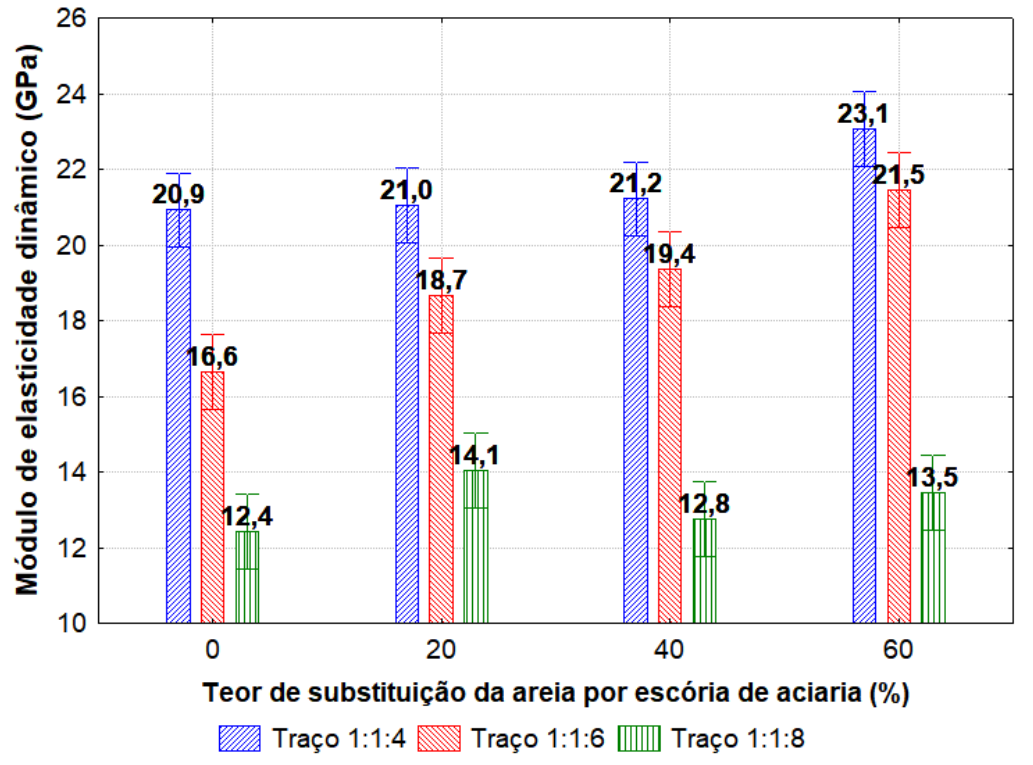

Figura 9: Módulo dinâmico das argamassas de acordo com o traço e o teor de substituição.

Constata-se que apesar das argamassas com maior teor de substituição apresentarem maior fator a/c, se comparadas com as argamassas de referência, as mesmas apresentam maior valor de módulo de elasticidade dinâmico. Isto se deve, possivelmente, devido a massa específica da escória $\left(3,86 \mathrm{~g} / \mathrm{cm}^{3}\right)$ ser superior ao da areia natural $(2,59$ $\mathrm{g} / \mathrm{cm}^{3}$ ). Em adição, estudos indicam que dureza do agregado de escória de aciaria é similar ou superior à de agregados de origem quartzosa e granítica (LUXAN et al., 2000). Tais características favorecem o aumento do módulo de elasticidade dinâmico das argamassas com maiores teores de escória de aciaria BSSF. No mesmo sentido, CARRIJO, em estudo experimental constatou que concretos com agregados mais densos tendem a gerar concretos com maiores 
valores de módulo de elasticidade.

Os altos valores obtidos podem prejudicar a durabilidade do revestimento, ao passo que quanto menor o valor do módulo, maior será a capacidade do revestimento de absorver deformações (SILVA, 2006; Nakamura, 2004). Logo, argamassas com maiores valores de módulo de elasticidade dinâmico são mais propensas a fissuração, podendo afetar a estanqueidade e consequentemente a vida útil do revestimento.

\section{CONCLUSÃO}

Como todos os materiais constituintes das argamassas e a metodologia de ensaios foram os mesmos, as diferenças no comportamento da resistência mecânica das argamassas estão relacionadas ao teor de escória de aciaria BSSF utilizada como substituição do agregado miúdo, areia.

Inicialmente, na definição da quantidade de água a ser utilizada, pode-se verificar que as argamassas com escória de aciaria demandam um maior fator a/c para o mesmo espalhamento. Fator que pode influenciar no aumento da porosidade das argamassas refletindo, também, no aumento da VPU, porém tal propriedade não sofreu uma alteração significativa.

Quanto à resistência mecânica, apesar de haver um relativo aumento da resistência à compressão e da resistência à tração na flexão, a Análise de Variância constatou que o teor de substituição não influencia na resistência das argamassas. Destaca-se que todas as argamassas se enquadraram nas classes P6 e R6 respectivamente para a resistência à compressão e tração na flexão, conforme NBR 13281 (ABNT, 2005).

\section{REFERÊNCIAS}

ABNT - ASSOCIAÇÃO BRASILEIRA DE NORMAS TÉCNICAS. NBR 13281: Argamassa para assentamento e revestimento de paredes e tetos - Requisitos. Rio de Janeiro, 2005.

ABNT - ASSOCIAÇÃO BRASILEIRA DE NORMAS TÉCNICAS. NBR 15630: Argamassa para assentamento e revestimento de paredes e tetos - Determinação do módulo de elasticidade dinâmico através da propagação de onda ultrassônica. Rio de Janeiro, 2008.

ABNT - ASSOCIAÇÃO BRASILEIRA DE NORMAS TÉCNICAS. NBR 16541: Argamassa para assentamento e revestimento de paredes e tetos - Preparo da mistura para a realização de ensaios, Rio de Janeiro, 2016.

ABNT - ASSOCIAÇÃO BRASILEIRA DE NORMAS TÉCNICAS. NBR NM 45: Agregados - Determinação da massa unitária e do volume de vazios. Rio de Janeiro, 2006.

ABNT - ASSOCIAÇÃO BRASILEIRA DE NORMAS TÉCNICAS. NBR NM 46: Agregados - Determinação do material fino que passa através da peneira $75 \mu \mathrm{m}$, por lavagem. Rio de Janeiro, 2003.

ABNT - ASSOCIAÇÃO BRASILEIRA DE NORMAS TÉCNICAS. NBR 13276: Argamassa para assentamento e revestimento de paredes e tetos - Determinação do índice de consistência. Rio de Janeiro, 2016.

ABNT - ASSOCIAÇÃO BRASILEIRA DE NORMAS TÉCNICAS. NBR 13279: Argamassa para assentamento e revestimento de paredes e tetos - Determinação da resistência à tração na flexão e à compressão. Rio de Janeiro, 2005.

ABNT - ASSOCIAÇÃO BRASILEIRA DE NORMAS TÉCNICAS. NBR 7211. Agregados para concreto Especificação, Rio de Janeiro, 2009.

ABNT - ASSOCIAÇÃO BRASILEIRA DE NORMAS TÉCNICAS. NBR NM 248: Agregados - Determinação da composição granulométrica. Rio de Janeiro, 2003.

ABNT - ASSOCIAÇÃO BRASILEIRA DE NORMAS TÉCNICAS. NBR NM 52: Agregado miúdo - Determinação da massa específica e massa específica aparente. Rio de Janeiro, 2009.

ABU-EISHAH S. I, EL-DIEB A. S, BEDIR M. S. Performance of concrete mixtures made with electric arc furnace (EAF) steel slag aggregate produced in the Arabian Gulf region. Construction and Building Materials v.34. pag.249256 , setembro, 2012. 
BRASIL. (2016). Departamento Nacional de produção mineral - Sumário Mineral. Brasília: DNPM, 2016.135 p. ISSN 01012053 Disponível em: http://www.dnpm.gov.br/dnpm/publicacoes/serie-estatisticas-e-economia-mineral/sumariomineral/sumario-mineral-brasileiro-2015.

CAMPOS, S. A.; RAFAEL, M. F. C.; CABRAL, A. E. B. Evaluation of steel slag of Companhia Siderúrgica do Pecém replacing fine aggregate on mortars. Procedia Structural Integrity. V. 11, pp. 145-152 (2018).

CARASEK, H.; ARAÚJO, R. C.;CASCUDO, O.;ANGELIM, R. "Parâmetros da areia que influenciam a consistência e a densidade de massadas argamassas de revestimento". Revista Matéria, v.21, n.3, pp. 714-732, jul. 2016.

CARASEK, H.; GIRARDI, A. C.C.; ARAÚJO, R. C.; ANGELIM, R.; CASCUDO, O. "Estudo e avaliação de agregados reciclados de resíduo de construção e demolição para argamassas de assentamento e de revestimento". Cerâmica v. 64, n. 370, pp. 288-300, Apr. 2018.

CHAVES, M. A.; SANTOS, B. E. Uso de imagens CBERS na identificação de áreas de extração de areia na Região Metropolitana de Salvador - BA XIII Simpósio Brasileiro de Sensoriamento Remoto, Florianópolis, Brasil, 21 a 26 abril de 2007. INPE.

CHEN,Z.; XIE,J.; XIAO,Y.; CHEN,J.; WU, S. Characteristics of bonding behavior between basic oxygen furnace slag and asphalt binder. Construction and Building Materials 64(2014) 60-66.

CARRIJO, P.M. Análise da influência da massa específica de agregados graúdos provenientes de resíduos de construção e demolição no desempenho mecânico do concreto. Dissertação de M.Sc, Politécnica da Universidade de São Paulo, Departamento de Engenharia de Construção Civil, São Paulo, SP, Brasil, 2005

DO Ó, S. W. Análise da retenção de água em argamassas de revestimento aditivadas. Dissertação de M.Sc, Universidade de Brasilia. Faculdade de Tecnologia. Brasilia,DF, Brasil, 2004.

FARAONE, N. TONELLO, G. FURNALI, E. MASCHIO, S. Steelmaking slag as aggregate for mortars: Effects of particle dimension on compression strength. Chemosphere 77 (2009) 1152-1156.

HADDAD, L.D.; COSTA, C.M.; LOPES, P. H. P.; CARVALHO JUNIOR, A. N.; SANTOS, W.J. “Análise da influência da granulometria do agregado miúdo nas propriedades mecânicas e de durabilidade das argamassas de revestimento". Ciência \& Engenharia. v. 25, n. 1, pp. 07-16, jan. - jun. 2016.

HANSEN, T. C. Recycling of Demolished Concrete and Masonry. RILEM Report 6. Ed Chapman \& Hall, London, 1992. 316p.

LACERDA, C. Traços de argamassa utilizando escória de aciaria elétrica. Tese de M. Sc. / Mestrado Profissional em Materiais/UniFOA, Volta Redonda, RJ, Brasil, 2015.

LOHANI, T. K.; PADHI, M.; DASH, K. P.; JENA, S. Optimum utilization of quarry dust as partial replacement of sand in concrete. Internacional Journal of Applied Sciences and Engineering Research, v. 1, n. 2, 391 -404, 2012.

LUXAN, M. P. SOTOLONGO, R. DORREGO, F. HERRERO, E. Characteristics of the slag produced in the fusion of scrap steel by eletric arc furnace. Cement and Concrete Research, Volume 30, 2000, p. 517-519

MOTZ, H. GEISELER, J. Products of steel slag an opportunity to save natural resources. Waste management. $21,2001$. p. 285-293.

NAKAKURA, E. H.; CINCOTTO, M. A. Análise dos requisitos de classificação de argamassas de assentamento e revestimento. In: BT/PCC/359 - Boletim Técnico da Escola Politécnica da USP, Departamento de Engenharia de Construção, São Paulo, 2004 
OUDA, A.S.; ABDEL-GAWWAD, "H.A.The effect of replacing sand by iron slag on physical, mechanical and radiological properties of cement mortar". HBRC Journal, v. 13, pp. 255-261, 2017.

OZTURK, M.; AKGOL, O.; SEVIM, U.K.; KARAASLAN, M.; DEMIRCI, M.; UNAL, "E. Experimental work on mechanical, electromagnetic and microwave shielding effectiveness properties of mortar containing electric arc furnace slag”. Construction and Building Materials, v. 165, pp. 58-63, 2018.

PEDRO, D. BRITO, J. VEIGA, R. Mortars Made with Fine Granulate from Shredded Tires Journal of Materials in Civil Engineering. v 25(4) p. 519-529, abril, 2013.

QASRAWI, H. The use of steel slag aggregate to enhance the mechanical properties of recycled aggregate concrete and retain the environment. Construction and Building Materials v. 54 p. 298-304, março 2014.

SANTAMARÍA-VICARIO, I.. RODRÍGUEZ, A. GONZÁLEZ, S. G; CALDERÓN, V. "Durability behavior of steelmaking slag masonry mortars". Materials and design, v. 97, pp. 307-315, 2016.

SILVA, N. G. Argamassa de Revestimento de Cimento, Cal e Areia Britada de Rocha Calcária. Dissertação de M.Sc, Universidade Federal do Paraná, Curitiba, PR, Brasil, 2006.

TOSSAVAINEN, M.; ENGSTROM, F.; YANG, Q.; MENAD, N.; LARSSON, M. L. BJORKMAN, B. Characteristics of steel slag under different cooling conditions. Waste Management. v. 27 p 1335-1344, 2007.

WANG, G. Determination of the expansion force of coarse steel slag aggregate. Construction and Building Materials v. 24 p. 1961-1966, outubro, 2010. 